\title{
30 ARE SCHOOLS IN MACEDONIA READY TO ACHIEVE CHILDREN'S ENVIRONMENTAL AND HEALTH POLICY PRIORITY GOALS?
}

doi:10.1136/injuryprev-2012-040590d.30

M Dimovska, D Gjorgjev, F Tozija. Institute of Public Health, Republic of Macedonia

Background Republic of Macedonia has committed itself to prepare an Action Plan (CEHAPE) to reduce and control the environmental risks which are responsible for $25-35 \%$ of the global burden of disease of school children.

Objectives To assess the level of awareness of school children about environmental health risks and readiness of schools to achieve CEHAPE priority goals related among others to injury prevention and control.

Material and Methods Cross-sectional study was conducted applying two survey questionnaires on a national representative sample of 1359 students (12-18 years) in the country.

Results Students are more concerned about air pollution from road traffic as an environmental health risk than road traffic injuries. Student awareness of injuries and violence is very low despite the high rate of injuries $(30 \%)$ and bulling $(10 \%)$. Student transport to school is mostly organised by public transport, taxi or private cars. Education for safe cycling is provided in 6 of 10 schools, without having 'safe routs for walking and cycling', neither places for keeping bicycles or separate entrance for cyclists. School plan for travelling is reported in 7 schools out of 13 .

Significance Since safety schools are among the priorities in the national children's environmental and health policy, active involvement of children and young people should be the fundament of this process. 